\title{
Effect of Lignin Glycosides Extracted from Pine Cones on the Human SIRT1 Promoter
}

\author{
Fumiaki Uchiumi ${ }^{1,2}$, Haruki Tachibana ${ }^{3}$, Steven Larsen ${ }^{2}$ and Sei-ichi Tanuma ${ }^{2,3,4,5 *}$ \\ ${ }^{1}$ Department of Gene Regulation, Faculty of Pharmaceutical Sciences, Tokyo University of Science, Noda-shi, Chiba-ken, Japan \\ ${ }^{2}$ Research Center for RNA Science, RIST, Tokyo University of Science, Noda-shi, Chiba-ken, Japan \\ ${ }^{3}$ Department of Biochemistry, Faculty of Pharmaceutical Sciences, Tokyo University of Science, Noda-shi, Chiba-ken, Japan \\ ${ }^{4}$ Genome and Drug Research Center, Tokyo University of Science, Noda-shi, Chiba 278-0022, Japan \\ ${ }^{5}$ Drug Creation Frontier Research Center, RIST, Tokyo University of Science, Noda-shi, Chiba 278-0022, Japan
}

\begin{abstract}
Sirtuins (SIRT1-7) and telomerase (TERT) are known to be involved in the regulation of cellular senescence/ aging processes. Resveratrol (Rsv), a natural polyphenol, which has been shown to extend the lifespan of diverse range of species. Furthermore, Rsv has been shown to activate SIRT1, the class III NAD+ dependent histone deacetylases (HDACs), directly in mammalian cells. Here, we examined the changes in promoter activities of the human SIRT1 and TERT genes after treatment with Rsv and lignin glycosidases/lignin carbohydrate complexes (LCC) extracted from pine cones of Pinus Karalensis. We constructed Luciferase (Luc) expression vectors, pGL4SIRT1 and pGL4-TERT, containing 396-bp and 263-bp of the 5'-upstream regions of human SIRT1 and TERT genes, respectively, which were then transfected into HeLa S3 cells. The Luc reporter plasmid assay revealed that treatment with the LCC increases not only SIRT1 but also TERT promoter activities more than that with Rsv. These results suggest that the LCC from pine cones induces expression of both SIRT1 and TERT genes, which is thought to have anti-aging effects.
\end{abstract}

Keywords: Aging; Cellular senescence; Gene regulation; Lignin glycosidases; Lignin carbohydrate complexs; Resveratrol; SIRT1; TERT

\section{Introduction}

It has been suggested that both cellular senescence and aging of organisms are accelerated by various factors, such as telomereshortening [1-3] and DNA damaging reactive oxygen species (ROS) that are mainly generated from mitochondria $[4,5]$. From genetic analyses, it has been shown that several genes, including daf- 2 and daf-16, which encode insulin/IGF1 receptor and transcription factor FoxO, respectively, play important roles in controlling the lifespan of C. elegans [6]. Studies of budding yeast showed that Sir2, a member of sirtuins having an $\mathrm{NAD}^{+}$-dependent protein deacetylase, has silencing action on chronological aging of yeast cells [7].

Recently, a natural polyphenolic compound Resveratrol (Rsv), which has a stimulating effect on sirtuin enzyme activity, has been shown to increase the lifespan of model animals [8-12]. Previously, we reported that trans-Resveratrol (Rsv) activates the human TERT promoter thus moderately inducing telomerase activity in HeLa-S3 cells [13]. Moreover, multiple transfection assays showed that promoter activation of the human shelterin protein encoding genes are up-regulated by Rsv treatment [14], suggesting that the natural polyphenol beneficially affects chromosomal stability by trans-activation of telomere maintenance factor encoding genes. Thus, Rsv and its related poly-phenols have been expected to be one of the candidate drugs for anti-aging therapeutics. However, it should be noted that Rsv has cytotoxic effects inducing cell death by apoptosis especially when it is used at high doses [15-17]. Therefore, in order to develop safe and effective anti-aging drugs, alternative natural compounds that induce SIRT1 and TERT gene expression should be investigated.

We previously showed that lignins and tannins, which are potential inhibitors of poly (ADP-ribose) glycohydrolase (PARG) [18], have many biological effects as antioxydants, antiviral, anticancer, and immuno-potentiating reagents [19,20]. Furthermore, tannic acid suppressed TPA-induction of HIV promoter activity in Jurkat cells $[21,22]$, suggesting that these natural compounds may affect transcription of various genes. In this study, we examined the effects of lignin carbohydrate complexes (LCC) extracted from pine cones of Pinus Karakensis on the promoter activities of the human TERT and SIRT1 genes by transient transfection and Luc reporter assay. Here, we describe the up-regulating effect of the LCC on these two promoter activities, suggesting that it is an attractive candidate for anti-aging drugs.

\section{Materials and Methods}

\section{Preparation of LCC from Pinus Karalensis pine cones}

Our preliminary experiments demonstrated that none of the active material from pine cones of Pinus karalensis was ethanol soluble, all of the following extractions were performed with extensive alcohol washing and acetone drying to remove fatty materials $[19,20]$. Pine cones thus prepared were extracted with $0.3 \mathrm{~N} \mathrm{NaOH}$ over night. The pine cone extracts were neutralized by $2 \mathrm{~N} \mathrm{HCl}$ to $\mathrm{pH} 5.5$, and then an equal volume of ethanol was added. The ethanol precipitates were collected and dialyzed against water. The dialyzates were lyophilized and purified by Sepharose LC-4B and Toyopal HW 40-F column chromatographies. The fractions were evaluated by pGL4-SIRT1

*Corresponding author: Sei-ichi Tanuma, Ph.D, Department of Biochemistry, Faculty of Pharmaceutical Sciences, Tokyo University of Science, 2641 Yamazaki, Noda-shi, Chiba-ken 278-8510, Japan, Tel: +81-4-7124-1501; Fax: +81-4-71213620; E-mail: tanuma@rs.noda.tus.ac.jp

Received December 27, 2011; Accepted January 28, 2012; Published January 30, 2012

Citation: Uchiumi F, Tachibana H, Larsen S, Tanuma SI (2013) Effect of Lignin Glycosides Extracted from Pine Cones on the Human SIRT1 Promoter. Pharm Anal Acta 4: 266. doi:10.4172/2153-2435.1000266

Copyright: $\odot 2013$ Uchiumi F, et al. This is an open-access article distributed unde the terms of the Creative Commons Attribution License, which permits unrestricted use, distribution, and reproduction in any medium, provided the original author and source are credited. 
Citation: Uchiumi F, Tachibana H, Larsen S, Tanuma SI (2012) Effect of Lignin Glycosides Extracted from Pine Cones on the Human SIRT1 Promoter. Pharm Anal Acta 4: 266. doi:10.4172/2153-2435.1000266

Page 2 of 4

reporter plasmid transfection and Luciferase (Luc) assay, and SIRT1 promoter activating fractions were collected. The partial structures of the purified LCC were analyzed by NMR (Figure 1). The molecular weight of the LCC is 8,000 to 10,000 containing uronic acid (10 to $20 \%$ of total sugar residues) and neutral sugars, including glucose, galactose, mannose, and arabinose ( 80 to $90 \%$ of total sugar residues).

\section{Cell culture}

Human cervical carcinoma (HeLa S3) cells were grown in Dulbecco's modified Eagle's (DME) medium (Nacarai, Tokyo, Japan), supplemented with $10 \%$ fetal bovine serum (FBS) (Sanko-Pure Chemical, Tokyo, Japan) and penicillin-streptomycin at $37^{\circ} \mathrm{C}$ in a humidified atmosphere with $5 \% \mathrm{CO}_{2}$.

\section{Construction of Luc reporter plasmids}

The Luc reporter plasmids carrying the human TERT promoter region was designated as described previously and named pGL4TERT $[13,23]$. The 5'-flanking region of the human SIRT1 gene was obtained by PCR with Prime Star Taq polymerase (Takara, Kyoto, Japan) and genomic DNA from HeLa S3 cells as a template. The sense and antisense primers used for PCR are hSIRT1-8570; 5'-TCGGTACCAAAACTTGAGCTGTTCCGGCGG-3', And AhSIRT1-8965; 5'-ATCTCGAGGGCCGCCTCGTCCGCCATCTTC-3', respectively. PCR products were digested with Kpn I and Xho I and then ligated into the multi-cloning site of the pGL4.10 [luc2] vector (Promega, Madison, WI), as described previously $[13,23,24]$. The resultant plasmid, containing 396-bp of 5'-upstream region of the human SIRT1 gene, was named pGL4-SIRT1.

\section{Transient transfection and luc assay}

Plasmid DNAs were transfected into HeLa S3 cells by the DEAEdextran method $[22,23]$. The DNA-transfected cells were divided into at least four dishes. After $24 \mathrm{~h}$ of transfection, pine cone LCC, trans-Resveratrol (Cayman Chem., Ann Arbor, MI) or other natural compounds were added to the culture medium. After a further $24 \mathrm{~h}$ of incubation, cells were collected and lysed with $100 \mu \mathrm{L}$ of $1 \mathrm{X}$ cell culture lysis reagent, containing $25 \mathrm{mM}$ Tris-phospate (pH 7.8), $2 \mathrm{mM}$ DTT, 2 mM 1,2-diaminocyclohexane-N,N,N',N',-tetraacetic acid, 10\% glycerol, and $1 \%$ Triton X-100, then mixed and centrifuged at 12,000 $\mathrm{x} g$ for $5 \mathrm{sec}$. The supernatant was stored at $-80^{\circ} \mathrm{C}$. The Luc assay was performed with a Luciferase assay system (Promega) and relative Luc activities were calculated as described previously $[22,23]$.

\section{Results}

\section{Isolation and characterization of the 5'-flanking region of the human SIRT1 gene}

The nucleotide sequence contained in the pGL4-SIRT1 revealed that the 0.4-kb region is identical to that of GenBank Accession No. NT_030059.13 (nucleotide No. 20448570 to 20448964) and the presence of the sequence containing the most 5'-upstream end of the cDNA (Accession No. NM_012238.4: GENE ID. 23411SIRT1). TFSEARCH program (http://www.cbrc.jp/research/db/TFSEARCH. $\mathrm{html}$ ) was executed for the 0.4 -kb region and characteristic recognition sequences of several known transcription factors were found (Figure 2). Although, no sequence similar to a TATA or CCAAT box was found, putative binding sites for CREB (-288 to -281$)$, GATA-1/2/3 $(-72$ to $-63,-55$ to $-46,+50$ to +59$)$, c-Myc $(-59$ to -48$)$, C/EBP $\beta(-270$ to -256$)$, USF/SREBP ( -141 to $-127,-59$ to -48$)$, Sp1 ( -83 to $-75,-65$ to $-57)$ and c-Ets (-182 to -172$)$ are located in the $0.4-\mathrm{kb}$ region (Figure 2$)$.

\section{Effect of LCC on the SIRT1 promoter}

To examine whether human SIRT1 promoter is affected by natural compounds, including LCC obtained from pine cone extracts (Figure 1), transient transfection and Luc assay were carried out. Luc activities of pGL4-SIRT1 transfected cells were normalized to that of non-treated control cells. As shown in Figure 3A left panel, relative Luc activity of the pGL4-SIRT1-transfected cells was prominently augmented by the addition of Rsv $(10 \mu \mathrm{M})$ or LCC $(100 \mu \mathrm{g} / \mathrm{ml})$ to the culture medium. In contrast, $100 \mu \mathrm{M}$ of Quercetin, which is a natural polyphenolic flavonoid [25], moderately up-regulated the SIRT1 promoter activity (Figure 3A, left).

To examine the dose-dependent response of LCC, HeLa S3 cells were treated with 0 to $100 \mu \mathrm{g} / \mathrm{mL}$ of LCC after $24 \mathrm{~h}$ of transfection and collected after further $24 \mathrm{~h}$ incubation (Figure 3B, open circle). The results indicated that $10 \mu \mathrm{g} / \mathrm{ml}$ of LCC is enough to induce SIRT1 promoter activity equal to Rsv $(10 \mu \mathrm{M})$ treatment. The half maximal effective concentration $\left(\mathrm{EC}_{50}\right)$ was calculated to be $18 \mu \mathrm{g} / \mathrm{ml}$. The endotoxin concentration in the LCC was estimated to be $15.7 \mathrm{EU} / \mathrm{mg}$, suggesting that it contains LPS only at low levels.

\section{Effect of LCC on the TERT promoter}

Similar experiments with pGL4-TERT plasmid were performed (Figure 3A, right). The results indicated that the 263-bp of the human TERT promoter region responded to Quercetin $(100 \mu \mathrm{M})$, Rsv $(10 \mu \mathrm{M})$, and LCC $(100 \mu \mathrm{g} / \mathrm{ml})$ in a similar manner as the $396-\mathrm{bp}$ of the SIRT1 promoter (Figure $3 \mathrm{~A}$, left). In addition, the LCC-dose response of the TERT promoter was almost the same as that of the SIRT1 promoter (Figure 3B).

\section{Discussion}

In this study, we have isolated a 5 '-flanking region of the human SIRT1 gene, and observed that Luc activity under the control of this 396-bp region showed greater response to the treatment with LCC

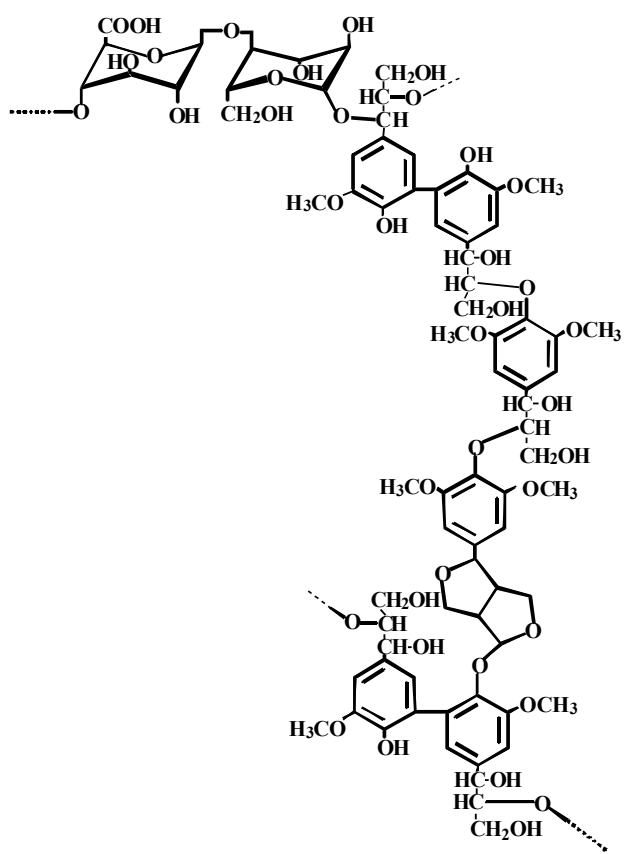

Figure 1: A typical partial structure of the LCC obtained from pine cone extracts. 
Citation: Uchiumi F, Tachibana H, Larsen S, Tanuma SI (2012) Effect of Lignin Glycosides Extracted from Pine Cones on the Human SIRT1 Promoter. Pharm Anal Acta 4: 266. doi:10.4172/2153-2435.1000266

than that with Rsv or Quercetin in HeLa S3 cells. This region has no apparent TATA-box but contains several well-known transcription factor binding sequences, including CREB, C/EBP $\beta$, c-ETS, USF, SREBP1, Sp1, GATA, and c-MYC binding elements (Figure 2). At present, the LCC- and Rsv-responsive elements in the SIRT1 promoter region have not been precisely determined. However, the 5 '-upstream regions of the WRN, BLM, TERT, $p 21$ (CDKN1A), and HELB genes, in which one or more Sp1/GC-box elements are commonly located, positively respond to the Rsv treatment in HeLa S3 cells $[13,26]$. The GC-box consensus sequence of the $\mathrm{Sp} 1$ transcription factor binding site is: $5^{\prime}-(\mathrm{G} / \mathrm{T}) \mathrm{GGGCGG}(\mathrm{G} / \mathrm{A})(\mathrm{G} / \mathrm{A})(\mathrm{C} / \mathrm{T}) \mathrm{3}^{\prime}$ or $5^{\prime}-(\mathrm{G} / \mathrm{T})(\mathrm{G} / \mathrm{A})$ GGCG $(\mathrm{G} / \mathrm{T})(\mathrm{G} / \mathrm{A})(\mathrm{G} / \mathrm{A})(\mathrm{C} / \mathrm{T})-3^{\prime}$ [27]. It has been shown that two GC-boxes, 5'-AGGGCGGGGG-3' and 5'GGGGCGGGTC -3' (Figure $2,-83$ to -74 and -66 to -57 , respectively), play important roles in the SIRT1 promoter activity [28]. Therefore, the tandem repeat of the Sp1 binding motif is possibly one of the candidate elements that respond to the LCC treatment. In addition, Rsv up-regulates cAMP level and CREB is known to be regulated by cAMP, and plays important roles in hormonal metabolisms, including that of the insulin signaling system [29]. These observations suggest that the CREB element located in the human SIRT1 promoter region (-288 to -281) may be also involved in the response to the LCC and Rsv treatments.

Rsv has been shown to affect essential signal transduction factors,

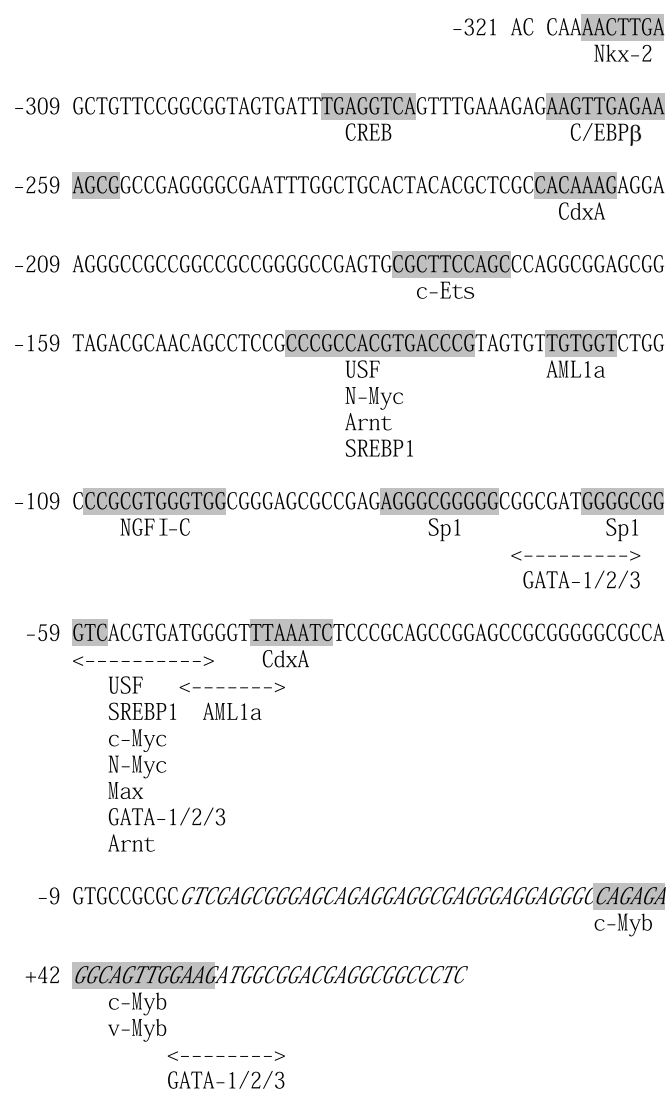

Figure 2: Nucleotide sequence of the 5'-flanking region of the human SIRT1 gene. The nucleotide sequence of the $0.4-\mathrm{kb}$ fragment obtained by PCR is shown. The most upstream of the cDNA (NM 012238.41) is designated nucleotide +1 . Putative transcription factor-binding sites (TFSEARCH score $>85$ ) are shaded or indicated by dotted arrows. Bold italic characters represent the cDNA sequence of the SIRT1 gene (Gene ID: 23411).
A

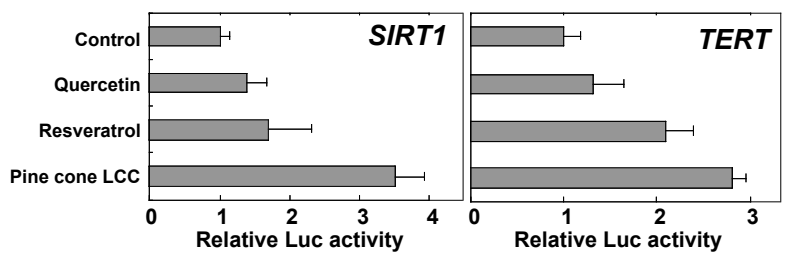

B

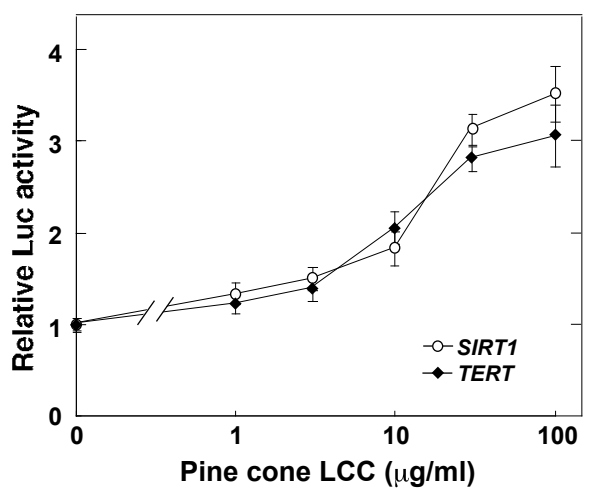

Figure 3: Effects of natural compounds on the promoter activities of the human SIRT1 and TERT genes. (A) The Luc reporter plasmids, pGL4-SIRT1 and pGL4TERT $[13,23]$, were transfected into HeLa S3 cells as described under Materials and Methods. After $24 \mathrm{~h}$ of transfection, cells were treated with Quercetin (100 $\mu \mathrm{M}), \operatorname{Rsv}(10 \mu \mathrm{M})$, and pine cone LCC $(100 \mu \mathrm{g} / \mathrm{ml})$, then harvested after a further $24 \mathrm{~h}$ incubation.

(B) Similar experiment as in (A) was performed with 0 to $100 \mu \mathrm{g} / \mathrm{ml}$ of the pine cone LCC. The results show relative Luc activities of the indicated Luc reporter plasmid-transfected cells relative to that of non-treated cells. The values are the mean $\pm \mathrm{SD}$ of four independent assays.

including AMPK [30,31] and FoxO [32], directly regulating the deacetylase activity of SIRT1. Other polyphenols, such as Quercetin and Catenins have been reported to moderately activate mammalian SIRT1 or yeast Sir2 enzyme activity $[10,25,33]$. However, they have no such effect in cellular system [25,33], rather they inhibit SIRT1 activity [33]. Therefore, regulation of lifespan and longevity of organisms might not only be controlled by SIRT1 enzyme activity but also by other factors involved in signal pathways between Rsv and SIRT1. Recently, it was suggested that Rsv has a hormetic effect on cells or organisms, that is to cause a biphasic dose response of various biological events [34]. Here, for the first time, we found the effective up-regulation of the SIRT1 and TERT gene promoter activities by the LCC treatment, suggesting that regulation of some transcription factors, including Sp1, responsible for the LCC may play important roles in control for life spans. Furthermore, the core structures of LCC might be useful to generate lead compounds for novel anti-aging drugs, which could simultaneously activate the SIRT1 and TERT promoter activities.

\section{Acknowledgments}

The authors are grateful to Takahiro Oyama, and Koetsu Nishi for their outstanding technical assistance. This work was supported in part by a Research Fellowship grant from the Research Center for RNA Science and Drug Creation Frontier Research Center, RIST, Tokyo University of Science.

\section{References}

1. O'Sullivan RJ, Karlseder J (2010) Telomeres: protecting chromosomes against genome instability. Nat Rev Mol Cell Biol 11: 171-181. 
Citation: Uchiumi F, Tachibana H, Larsen S, Tanuma SI (2012) Effect of Lignin Glycosides Extracted from Pine Cones on the Human SIRT1 Promoter. Pharm Anal Acta 4: 266. doi:10.4172/2153-2435.1000266

2. Blackburn E (2006) Chapter 1: A history of telomere biology. In: Telomeres ( $2^{\text {nd }}$ edn), (de Lang T, Lundblad V, Blackburn E, Eds.), Cold Spring Harbor Laboratory Press, NY: 1-19.

3. Vijg J (2007) Chapter 5: Genome instability and accelerated aging. In: Aging of the Genome: The Dual Role of DNA in Life and Death, Oxford University Press, NY: 151-180.

4. Robb EL, Page MM, Stuart JA (2009) Mitochondria, cellular stress resistance, somatic cell depletion and lifespan. Curr Aging Sci 2: 12-27.

5. Benz CC, Yau C (2008) Ageing, oxidative stress and cancer: paradigms in parallax. Nat Rev Cancer 8: 875-879.

6. Kenyon CJ (2010) The genetics of aging. Nature 464: 504-512.

7. Kaeberlein M (2010) Lessons on longevity from budding yeast. Nature 464 513-519.

8. Stefani M, Markus MA, Lin RC, Pinese M, Dawes IW, et al. (2007) The effect of resveratrol on a cell model of human aging. Ann NY Acad Sci 1114: 407-418.

9. Kaeberlein M (2010) Resveratrol and rapamycin: are they anti-aging drugs? Bioessays 32: 96-99.

10. Howitz KT, Bitterman KJ, Cohen HY, Lamming DW, Lavu S, et al. (2003) Smal molecule activators of sirtuins extend Saccharomyces cerevisiae life span. Nature 425: 191-196.

11. Wood JG, Rogina B, Lavul S, Howitz K, Helfand SL, et al. (2004) Sirtuin activators mimic caloric restriction and delay aging in metazoans. Nature 430 686-689.

12. Viswanathan M, Kim SK, Berdichevsky A, Guarente LA (2005) A role for SIR2.1 regulation of ER stress response genes in determining $C$. elegans life span. Dev Cell 9: 605-615.

13. Uchiumi F, Watanabe T, Hasegawa S, Hoshi T, Higami Y, et al. (2011) The effect of resveratrol on the Werner Syndrome RecQ helicase gene and telomerase activity. Curr Aging Sci 4: 1-7.

14. Uchiumi F, Oyama T, Ozaki K, Tanuma S (2011) Chapter 29: Characterization of 5 '-flanking regions of various human telomere maintenance factor-encoding genes. In: DNA Repair (Kruman I, Ed.), InTech-Open Access Publisher, Inc, Rijeka, Croatia: 585-596.

15. Calabrese EJ, Mattson MP, Calabrase V (2010) Resveratrol commonly displays hormesis: Occurrence and biomedical significance. Hum Exp Toxico 29: 980-1015.

16. Gogada R, Prabhu V, Amadori M, Scott R, Hashmi S, et al. (2011) Resveratro induces p53-independent, X-linked inhibitor of apoptosis protein (XIAP)mediated Bax protein oligomerization on mitochondria to initiate cytochrome $\mathrm{C}$ release and caspase activation. J Biol Chem 286: 28749-28760.

17. Lin HY, Tang HY, Davis FB, Davis PJ (2011) Resveratrol and apoptosis. Ann NY Acad Sci 1215: 79-88.

18. Tanuma S, Tsai YJ, Sakagami H, Konno K, Endo H (1989) Lignin inhibits (ADPribose)n glycohydrolase activity. Biochem Int 19: 1395-1402.

19. Sakagami H, Kawazoe Y, Komatsu N, Simpson A, Nonoyama M, et al. (1991)
Antitumor, antiviral and immunopotentiating activities of pine cone extracts: potential medicinal efficacy of natural and synthetic lignin-related materials. Anticancer Res 11: 881-888.

20. Blokhina O, Virolainen E, Fagerstedt KV (2003) Antioxidants, oxidative damage and oxygen deprivation stress: a review. Annals Botany 91: 179-194.

21. Uchiumi F, Maruta H, Inoue J, Yamamoto T, Tanuma S (1996) Inhibitory effect of tannic acid on human immunodeficiency virus promoter activity induced by 12-O-tetra decanoyl phorbol-13-acetate in Jurkat T-cells. Biochem Biophys Res Commun 220: 411-417.

22. Uchiumi F, Hatano T, Ito H, Yoshida T, Tanuma S (2003) Transcriptional suppression of the HIV promoter by natural compounds. Antiviral Res 58: 8998.

23. Zhou B, Ikejima T, Watanabe T, Iwakoshi K, Idei Y, et al. (2009) The effect of 2-deoxy-D-glucose on Werner syndrome RecQ helicase gene. FEBS Lett 583 1331-1336.

24. Uchiumi F, Watanabe T, Tanuma S. (2010) Characterization of various promoter regions of human DNA helicase-encoding genes and identification of duplicated ets (GGAA) motifs as an essential transcription regulatory element. Exp Cell Res 316: 1523-1534.

25. Chung S, Yao H, Caito S, Hwang J-W, Arunachalam G, et al. (2010) Regulation of SIRT1 in cellular functions: role of polyphenols. Arch Biochem Biophys 501 79-90.

26. Uchiumi F, Higami Y, Tanuma S (2010) Chapter 5: Regulations of telomerase activity and $W R N$ gene expression. In: Telomerase: Composition, Functions and Clinical Implications (Gagnon AN, Ed.), Nova Science Publishers, Inc, Hauppauge, NY: 95-103.

27. Wieratra I (2008) Sp1: Emerging roles-Beyond constitutive activation of TATAless housekeeping genes. Biochem Biophys Res Commun 372: 1-13.

28. Okazaki M, Iwasaki Y, Nishiyama M, Taguchi T, Tsugita M, et al. (2010) PPARbeta/delta regulates the human SIRT1 gene transcription via Sp1. Endocrine J 57: 403-413.

29. Altarejos JY, Montminy M (2011) CREB and the CRTC co-activators: sensors for hormonal and metabolic signals. Nat Rev Mol Cell Biol 12: 141-151.

30. Baile CA, Yang J-Y, Rayalam S, Hartzell DL, Lai CY, et al. (2011) Effect of resveratrol on fat mobilization. Ann NY Acad Sci 1215: 40-47.

31. Canto C, Auwerx J (2010) AMP-activated protein kinase and its downstream transcriptional pathways. Cell Mol Life Sci 67: 3407-3423.

32. Stefani M, Markus MA, Lin RCY, Pinese M, Dawes IW, et al. (2007) The effect of resveratrol on a cell model of human aging. Ann NY Acad Sci 1114: 407-418

33. de Boer VC, de Goffau MC, Arts IC, Hollman PC, Keijer J (2006) SIRT1 stimulation by polyphenols is affected by their stability and metabolism. Mech Aging Dev 127: 618-627.

34. Calabrese E, Mattson MP, Calabrese V (2010) Resveratrol commonly displays hormesis: Occurrence and biomedical significance. Hum Exp Toxicol 29: 9801015.
This article was originally published in a special issue, Advances in natural polymers as pharmaceutical handled by Editor(s). Dr. Ikoni Ogaji, University of Jos, Nigeria 